\title{
Energetic electron precipitation during substorm injection events: High-latitude fluxes and an unexpected midlatitude signature
}

\author{
Mark A. Clilverd, ${ }^{1}$ Craig J. Rodger, ${ }^{2}$ James Brundell, ${ }^{3}$ John Bähr, ${ }^{2}$ Neil Cobbett, ${ }^{1}$ \\ Tracy Moffat-Griffin, ${ }^{1}$ Andrew J. Kavanagh, ${ }^{4}$ Annika Seppälä, ${ }^{5,6}$ Neil. R. Thomson, ${ }^{2}$ \\ Reiner H. W. Friedel, ${ }^{7}$ and Frederick W. Menk ${ }^{8}$ \\ Received 28 March 2008; revised 10 June 2008; accepted 1 August 2008; published 30 October 2008.
}

[1] Geosynchronous Los Alamos National Laboratory (LANL-97A) satellite particle data, riometer data, and radio wave data recorded at high geomagnetic latitudes in the region south of Australia and New Zealand are used to perform the first complete modeling study of the effect of substorm electron precipitation fluxes on low-frequency radio wave propagation conditions associated with dispersionless substorm injection events. We find that the precipitated electron energy spectrum is consistent with an $e$-folding energy of $50 \mathrm{keV}$ for energies $<400 \mathrm{keV}$ but also contains higher fluxes of electrons from 400 to $2000 \mathrm{keV}$. To reproduce the peak subionospheric radio wave absorption signatures seen at Casey (Australian Antarctic Division), and the peak riometer absorption observed at Macquarie Island, requires the precipitation of $50-90 \%$ of the peak fluxes observed by LANL-97A. Additionally, there is a concurrent and previously unreported substorm signature at $L<2.8$, observed as a substorm-associated phase advance on radio waves propagating between Australia and New Zealand. Two mechanisms are discussed to explain the phase advances. We find that the most likely mechanism is the triggering of wave-induced electron precipitation caused by waves enhanced in the plasmasphere during the substorm and that either plasmaspheric hiss waves or electromagnetic ion cyclotron waves are a potential source capable of precipitating the type of high-energy electron spectrum required. However, the presence of these waves at such low $L$ shells has not been confirmed in this study.

Citation: Clilverd, M. A., et al. (2008), Energetic electron precipitation during substorm injection events: High-latitude fluxes and an unexpected midlatitude signature, J. Geophys. Res., 113, A10311, doi:10.1029/2008JA013220.

\section{Introduction}

[2] In this study we analyze ground-based ionospheric data from middle and high latitudes in the region around Australia and New Zealand during dispersionless substorm injection events. We use data from 2005 to 2007 to show that ionization signatures of substorm injection events can be observed at both $L \sim 4-12$ and $L \sim 2.4-2.8$, despite the well known low-latitude limit of particle precipitation being $L \sim 4.0$ [Berkey et al., 1974]. We use radio waves, riometers

\footnotetext{
${ }^{1}$ Physical Sciences Division, National Environmental Research Council, British Antarctic Survey, Cambridge, U.K.

${ }^{2}$ Department of Physics, University of Otago, Dunedin, New Zealand.

${ }^{3}$ Dunedin, New Zealand.

${ }^{4}$ Space Plasma Environment and Radio Science Group, Department of Communication Systems, Lancaster University, Lancaster, U.K.

${ }^{5}$ Earth Observation, Finnish Meteorological Institute, Helsinki, Finland.

${ }^{6}$ Now at Physical Sciences Division, National Environmental Research Council, British Antarctic Survey, Cambridge, U.K.

${ }^{7}$ Los Alamos National Laboratory, Los Alamos, New Mexico, USA.

${ }^{8}$ School of Mathematical and Physical Sciences and Cooperative Research Centre for Satellite Systems, University of Newcastle, Callaghan, New South Wales, Australia.

Copyright 2008 by the American Geophysical Union. 0148-0227/08/2008JA013220\$09.00
}

and geostationary spacecraft data to show that the timing of the precipitation events at $L \sim 2.4-2.8$ is the same as at $L \sim 5$, but delayed with respect to the injection signature at geostationary orbit $(L=6.6)$.

[3] Substorm injection events were comprehensively mapped by Berkey et al. [1974] using about 40 Northern Hemisphere riometers in the IQSY (1964-1965) and IASY (1969). Typically, energetic electron precipitation from a substorm occurs near midnight, rapidly expanding eastward with velocities that correspond to electron drift velocities associated with energies of 50-300 keV. Initially the riometer absorption maximum is located close to $65^{\circ}$ geomagnetic latitude $(L \sim 6)$ but expands within $15 \mathrm{~min}$ to cover a latitude range of $60-73^{\circ}$ geomagnetic $(L=4-12)$. This latitude range is consistent with the observations from particle detectors on DMSP flights [Sandholt et al., 2002]. After $15 \mathrm{~min}$ the longitudinal extent of the substorm precipitation region is $\sim 100^{\circ}$. The longitudinal expansion can continue for more than an hour until substorm signatures are observed at most local times, although no further increase in latitudinal extent occurs. The electron energies involved in substorm injections seen by satellites such as LANL are typically $50-$ $1000 \mathrm{keV}$, with the highest fluxes occurring at the lowest energies [Baker et al., 1985]. While the satellite observa- 


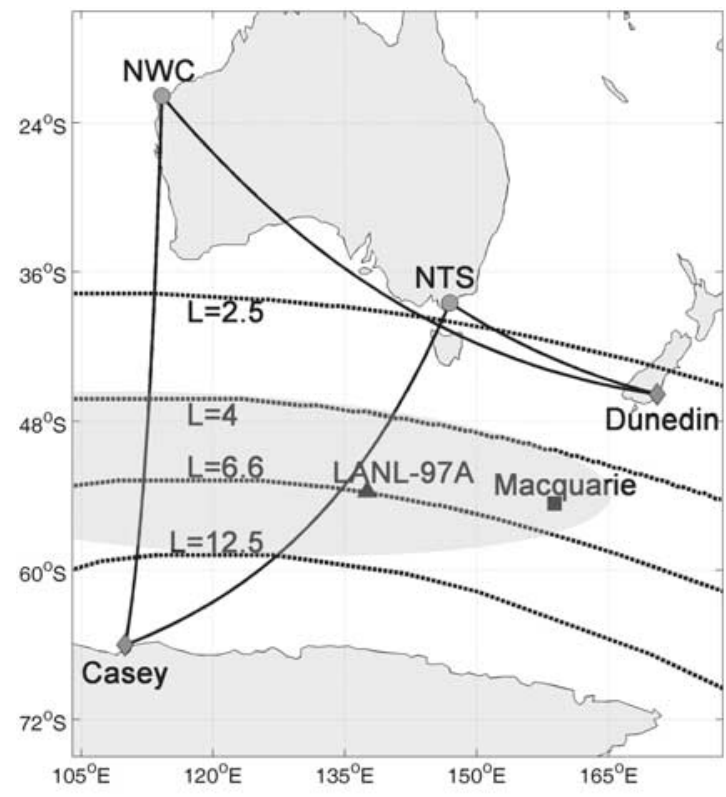

Figure 1. The location of subionospheric propagation paths from VLF transmitters in Australia to the AntarcticArctic Radiation-Belt Dynamic Deposition VLF Atmospheric Research Konsortia (AARDDVARK) receiver sites at Dunedin and Casey. The location of the LANL-97A geomagnetic footprint in the Southern Hemisphere during the March 2006 period studied in this paper is indicated by a triangle. The location of the Macquarie Island riometer is indicated by a square. The gray oval represents a typical region of substorm precipitation shortly after onset, where the $L$-shell contours indicate the likely limits of precipitation.

tions provide some information on the energy spectra of the injected electrons, and the fluxes in drift orbit, it is very difficult to determine what proportion of the electrons are being precipitated into the atmosphere through onboard satellite measurements. The primary difficulty is in making observations of electron populations in the spatially narrow loss cone, particularly around the geomagnetic equator where geostationary satellites reside.

[4] The injection of energetic electrons during a substorm has been modeled by considering an electromagnetic pulse propagating earthward, interacting with a preexisting electron population [Sarris et al., 2002]. The rate of inward drift of the electron population driven by radial diffusion has been shown to gradually decrease with decreasing $L$ shell. Close to the injection latitude, that is, at a single local time, the radial motion is typically $25 \mathrm{~km} \mathrm{~s}^{-1}$, slowing to $\sim 15 \mathrm{~km} \mathrm{~s}^{-1}$ at about $L=5$. Calculations at $L$ shells below $L=4$ have not be made because of the observed limits of substorm injection precipitation, but simple extrapolation of the published data suggests speeds of $\sim 10 \mathrm{~km} \mathrm{~s}^{-1}$ at $L=2.8$, assuming it is possible for the injection to penetrate inside $L=4$. The results of Sarris et al. [2002] suggest that between the time delay of an injection signature at geostationary obit and $L=5.4$ is $5 \mathrm{~min}$, while for the same injection to reach $L=2.8$ would be a further $\sim 20 \mathrm{~min}$.

[5] Energetic electron precipitation during substorms has been studied using riometers [e.g., Jelly and Brice, 1967], forward scatter radar [e.g., Bailey, 1968], and VLF radio waves [e.g., Thorne and Larsen, 1976]. The VLF radio wave technique has an advantage in that it is most sensitive to ionization caused by relativistic electron precipitation energies, typically $>100 \mathrm{keV}$, as these energies ionize the neutral atmosphere in the Earth-ionosphere waveguide, that is, at altitudes below $\sim 70 \mathrm{~km}$. Thorne and Larsen [1976, and references therein] reported that electron fluxes of $\geq 10^{3}$ el. $\mathrm{cm}^{-2} \mathrm{~s}^{-1} \mathrm{sr}^{-1}$ were required at energies of $>200 \mathrm{keV}$ in order to account for radio signal disturbances during substorms, observed over the latitudes $4.5 \leq L \leq$ 6.0. Larsen and Thomas [1974] used the ERSO 1A satellite to estimate that the trapped electron spectrum during a substorm could be represented by an $e$-folding energy of about $50 \mathrm{keV}$ (using 176-434 keV energies). The energy spectrum of the electron precipitation into the atmosphere was found to be of the same form as the trapped fluxes [Rosenberg et al., 1972] with the maximum precipitated fluxes comparable with the trapped fluxes [Larsen and Thomas, 1974].

[6] In this study we use LANL particle data, riometer data, and radio wave data recorded at high geomagnetic latitudes to identify the occurrence of substorm injection events in a region south of Australia and New Zealand. Data sets from high-latitude locations (Casey and Macquarie Island, Australian Antarctic Division) and the geostationary satellite LANL-97A are used to describe the high-latitude electron precipitation driven by dispersionless substorm injections. Additionally, we present radio wave data recorded at Dunedin, New Zealand to show that there is a concurrent and unexpected substorm signature at $L<2.8$, but that no clear signature of the substorms can be detected in a riometer also located in Dunedin. We discuss the potential mechanisms that could cause the observed radio wave signature, including the precipitation of radiation belt electrons by electromagnetic ion cyclotron waves, and the possibility of distant scattering of radio waves by the expected ionospheric ionization feature at $L>4$ in a similar way to medium-latitude Trimpi.

\section{Experimental Setup}

[7] This paper combines data from subionospheric VLF radio wave receivers, a geostationary LANL satellite, and ground-based riometers to describe the spatial variability of energetic particle precipitation into the middle atmosphere during substorm events. This section describes each instrument, and its relevance to this study. An overview of the experimental setup is given in Figure 1 which shows a map of the Australia/New Zealand/Antarctic region, and includes the locations of all of the instruments described in this section. The oval shown in Figure 1 depicts a typical substorm precipitation region shortly after the onset, determined from the analysis of riometer data [Berkey et al., 1974].

[8] Here we use narrowband subionospheric VLF radio wave data, transmitted from two Australian sites (NTS, $18.6 \mathrm{kHz}$, and NWC $19.8 \mathrm{kHz}$ ) received at two sites: Casey, Antarctica $\left(66.3^{\circ} \mathrm{S}, 110.5^{\circ} \mathrm{E}, L>999\right)$, and Dunedin, New Zealand $\left(45.9^{\circ} \mathrm{S}, 170.5^{\circ} \mathrm{E}, L=2.8\right)$. These receiving sites are part of the Antarctic-Arctic Radiation-Belt Dynamic Deposition VLF Atmospheric Research Konsortia 
(AARDDVARK, for a comprehensive description of the array visit www.physics.otago.ac.nz/space/AARDDVARK homepage.htm). The effects of changing ionization conditions in the mesosphere, due to energetic particle precipitation, can be observed along the propagation path between a VLF transmitter and a receiver. Subionospheric propagation is sensitive to ionization located below about $90 \mathrm{~km}$. The effect of increased ionization on the propagating signals can be seen as either an increase or decrease in signal amplitude or phase depending on the modal mixture of each signal observed [Barr et al., 2000; Clilverd et al., 2006b]. This study reports only amplitude results from Casey because there are no current measurements of phase available from that site. Phase and amplitude data are available at Dunedin, although we typically show phase only to reduce the number of plots per figure, and because the phase response is more consistent from substorm to substorm. The great circle paths from NWC and NTS received at Dunedin and Casey are shown in Figure 1.

[9] The LANL spacecraft data used in this study are from the Synchronous Orbit Particle Analyzer (SOPA) on LANL97A $\left(L \sim 6.6,138^{\circ} \mathrm{E}\right)$. We concentrate on data from LANL97A because the $L$-shell footprint of the satellite is located in the ocean south of Australia, and lies close to the great circle paths of signals from NTS and NWC received at Casey. In subsequent analysis we show the LANL-97A electron flux in the energy range $75-105 \mathrm{keV}$ [Belian et al., 1992] because electrons with these energies will create ionization at altitudes of $\sim 80 \mathrm{~km}$, and thus significantly influence the electron density profile of the nighttime lower ionosphere.

[10] The riometer data used in this study are provided from instruments located at Dunedin $\left(45.9^{\circ} \mathrm{S}, 170.5^{\circ} \mathrm{E}\right.$, $L=2.8)$ and Macquarie Island $\left(54.5^{\circ} \mathrm{S}, 158.9^{\circ} \mathrm{E}, L=5.4\right)$. The riometers are wide-beam, $30 \mathrm{MHz}$, vertical pointing parallel dipole systems, with time resolutions of $1-10 \mathrm{~s}$, although we typically present $1 \mathrm{~min}$ average data. Riometers [Little and Leinbach, 1959] will observe the integrated absorption of cosmic radio noise through the ionosphere, with increased absorption due to additional ionization due to both proton and electron precipitation. The dominant altitude of the absorption is typically in the range $70-100 \mathrm{~km}$, that is, biased toward relatively soft particle energies ( $\sim 30 \mathrm{keV}$ electrons).

\section{Results}

[11] The first substorm event period is shown in Figure 2. Figures $2 \mathrm{a}-2 \mathrm{e}$ show (in descending geomagnetic latitude) the amplitude variation of the NTS transmitter received at Casey, the LANL-97A 75-105 keV electron flux, the Macquarie Island riometer absorption, the phase of NTS received at Dunedin, and the phase of NWC received at
Dunedin. The time axis shows the period 1200-1600 UT on 1 March 2006. The local time in the plot is approximately $\mathrm{UT}+9$, and thus the plot represents the time period centered around local midnight. The LANL-97A flux data shows that a substorm injection started at 1336 UT (close to 2300 MLT), and this time is highlighted by a dotted vertical line. We use 75-105 keV electron flux data from LANL-97A because precipitating electrons in that energy range will create ionization at altitudes below the nighttime $D$ region and thus should be detected using subionospherically propagating radio waves, for example, the NTS signal received at Casey. The LANL-97A energy channels show that the substorm injection at 1336 UT is dispersionless (not shown here), and thus the local time of the injection region is close to the local time of the Southern Hemisphere footprint of LANL-97A. In Figures $2 \mathrm{a}-2 \mathrm{e}$ the vertical dotted lines represent the time at which the substorm signature is observed, while the dashed quasi-horizontal lines represent the undisturbed behavior of each signal.

[12] In Figure 2 it can been seen that the Casey radio wave amplitude decrease and the LANL-97A injection timing are very similar. The Casey radio wave amplitude changes show a similar temporal variation to the LANL97A fluxes, last about the same length of time $(\sim 0.6 \mathrm{~h})$, and have a peak effect (in this case $12 \mathrm{~dB}$ ) at about the same time. Further coincidence is seen in the decrease in amplitude at about $1500 \mathrm{UT}$, which is consistent with the return of $100 \mathrm{keV}$ electrons having drifted around the Earth at $L=6.6$ (drift period $1.33 \mathrm{~h}$ ) which can also be seen in the LANL97A fluxes. The absorption signature in the Macquarie Island riometer starts $\sim 0.1 \mathrm{~h}(\sim 6 \mathrm{~min})$ later than the LANL-97A timing, at 1342 UT, consistent with penetration to lower $L$ shells. However, the $40-60^{\circ}$ phase changes in the radio wave signals received at Dunedin occur at the same time as the $2.5 \mathrm{~dB}$ absorption peak in the Macquarie riometer. Phase changes of this magnitude are often associated with significant perturbations of the ionosphere such as solar flare events [Thomson et al., 2005] and are substantially larger than whistler-induced precipitation signatures seen at midlatitudes [Helliwell et al., 1973; Barr et al., 2000]. The peak effects in absorption and phase change are not observed at the same time as the LANL-97A flux peak, but the Macquarie riometer and Dunedin radio wave data do show effects lasting approximately the same length of time, that is, $1.5 \mathrm{~h}$.

[13] A second substorm event is shown in Figure 3. The event occurred at 1542 UT on 27 March 2006 ( 0200 LT) and is plotted in the same format as Figure 2. Figure 3a shows the change in radio wave amplitude for the NTS signal received at Casey. As in Figure 2, the start of the substorm in the LANL-97A electron fluxes is the same as that seen in the radio wave data from Casey, but the Macquarie riometer and Dunedin subionospheric data again

Figure 2. Observations of a substorm on 1 March 2006. (a) The NTS-Casey amplitude data (solid line) for 1200-1600 UT (2100-0100 LT, LT = UT + 9) plotted against a quiet day curve (dashed line). The vertical dotted line represents the start of the substorm effect. (b) The LANL-97A $75-105 \mathrm{keV}$ fluxes for the same period. (c) The Macquarie Island riometer absorption. The start of the absorption event is also noted by a vertical dotted line, although it should be noted that it is not placed at the same time as in Figures 2a and 2b. (d and e) The phase change of the NWC and NTS transmitter signals received at Dunedin during the same period. A dashed line represents the quiet time phase variations expected at this time of night. 

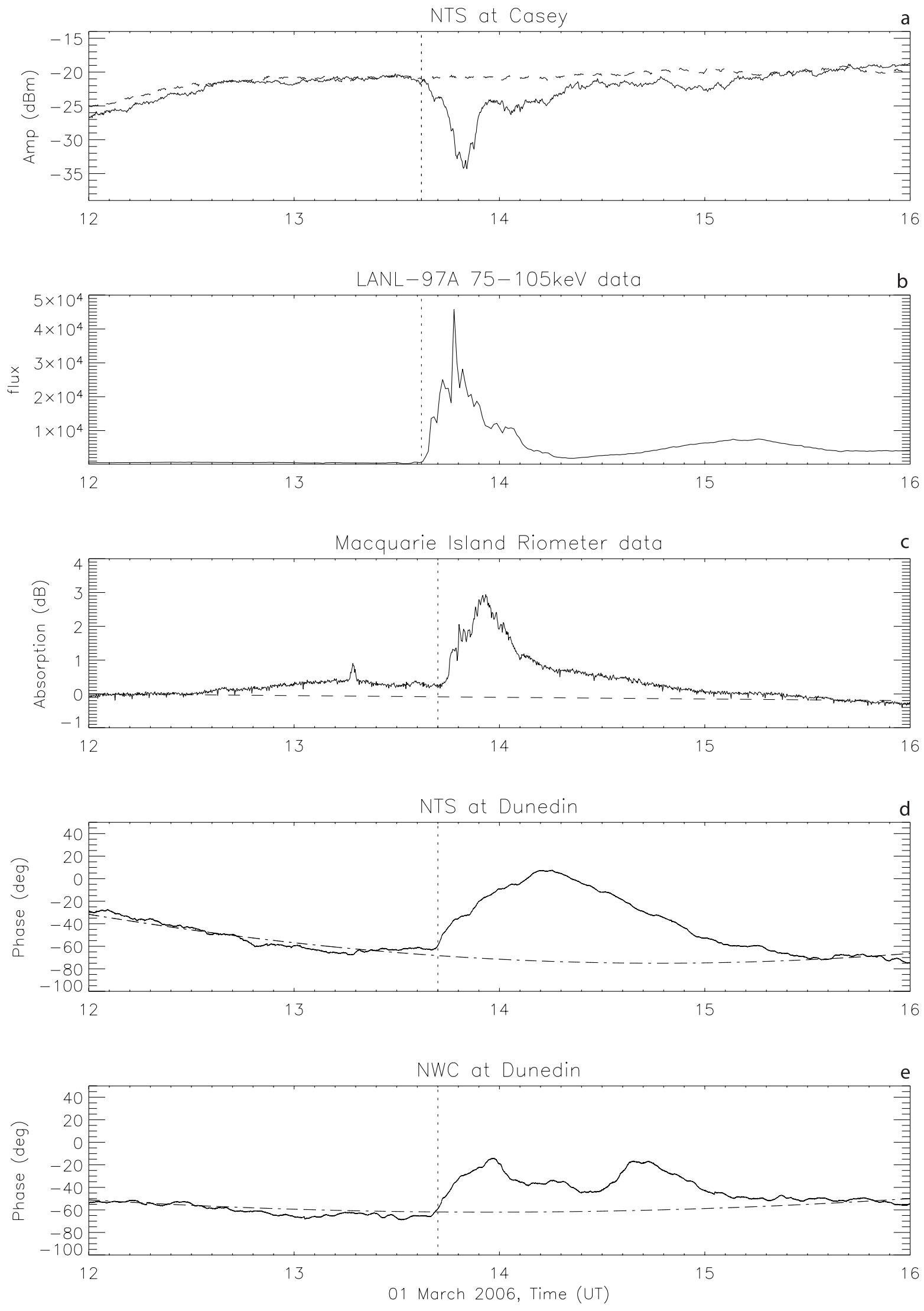

Figure 2 

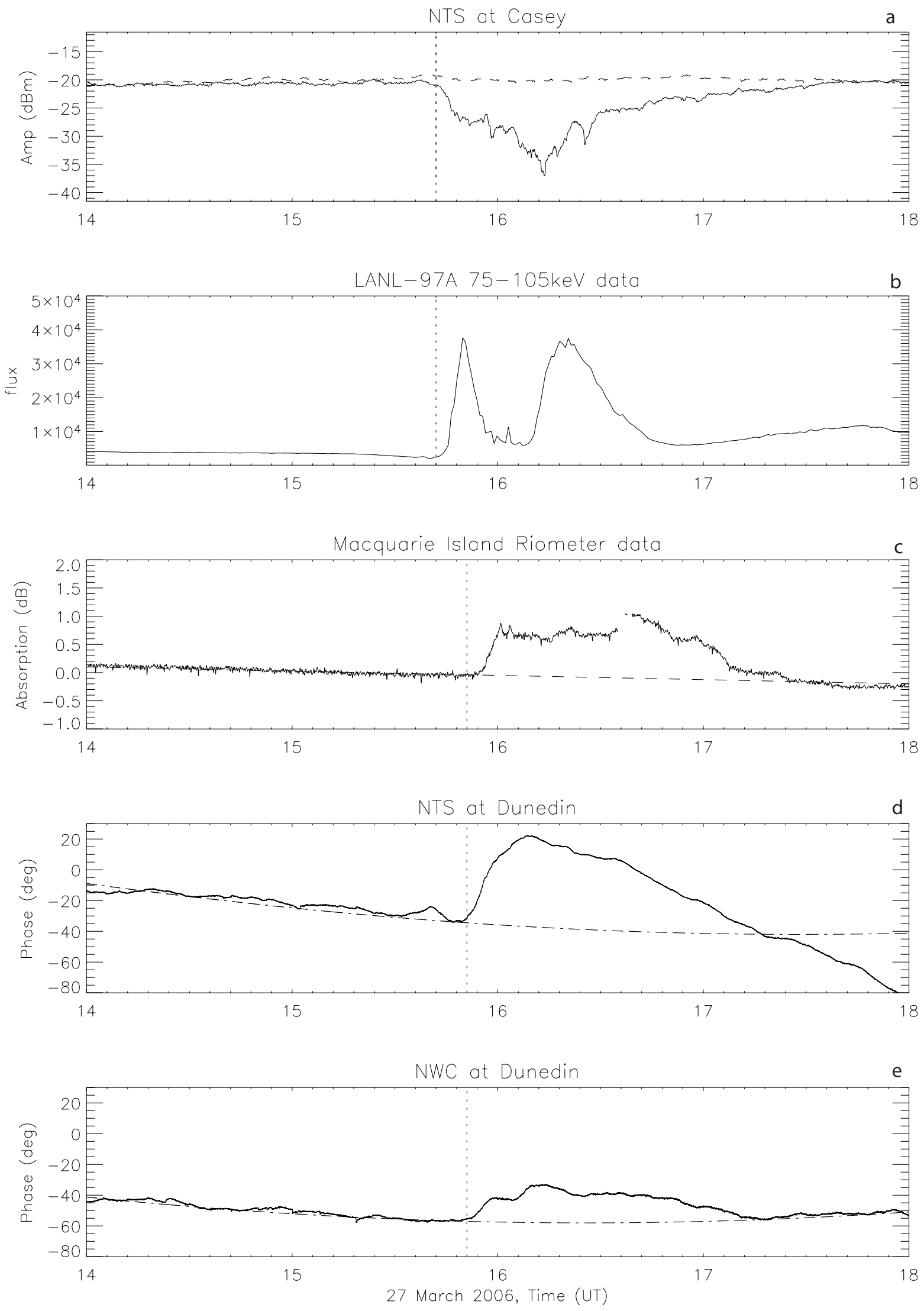

Figure 3. (a-e) Observations of a substorm on 27 March 2006. Format is the same as that for Figure 2. 
Table 1. Properties of the NTS to Dunedin Substorm-Associated Phase Advances Observed in 2006 and 2007, Including the Delay Time of the Macquarie Island Riometer Signal Compared With the LANL-Spacecraft Injection Onset Time and the Subsequent Delay From the Macquarie Riometer Onset to the Radio Wave Phase Advance Onset on NTS Transmissions Observed at Dunedin

\begin{tabular}{|c|c|c|c|c|c|}
\hline Date & $\begin{array}{l}\text { LANL Onset Time } \\
(\mathrm{UT})\end{array}$ & $\begin{array}{c}\text { Delay Time to Macquarie } \\
\text { Riometer (hours) }\end{array}$ & $\begin{array}{c}\text { NTS Phase } \\
\text { Advance (degrees) }\end{array}$ & $\begin{array}{l}\text { Phase Advance } \\
\text { Duration (hours) }\end{array}$ & $\begin{array}{l}\text { Subsequent Delay } \\
\text { Time to Phase } \\
\text { Advance (hours) }\end{array}$ \\
\hline 27 Feb 2007 & 1536 & 0.00 & 70 & 1.4 & 0.70 \\
\hline 1 Mar 2006 & 1336 & 0.10 & 75 & 1.6 & 0.00 \\
\hline 6 Mar 2006 & 1351 & 0.10 & 40 & 2.0 & 0.00 \\
\hline 27 Mar 2006 & 1542 & 0.15 & 55 & 1.5 & 0.00 \\
\hline 5 Apr 2007 & 1233 & 0.10 & 50 & 1.3 & 0.00 \\
\hline 22 Apr 2007 & 1100 & 0.15 & 20 & 1.0 & 0.00 \\
\hline 15 Jun 2006 & 1411 & 0.02 & 5 & 1.1 & 0.07 \\
\hline 7 Sep 2006 & 1300 & 0.00 & 0 & - & - \\
\hline
\end{tabular}

start after $\mathrm{a} \sim 0.15 \mathrm{~h}(\sim 10 \mathrm{~min})$ delay. Although the LANL97A injection signature shows a two-peaked structure during the substorm, none of the ground-based experiments show this, and instead, show a gradual rise to a maximum effect $\sim 0.3-0.6 \mathrm{~h}$ after the start of the event. Similarly, all the ground-based experiments showed that the substorm event lasted until $\sim 1730$ UT, while the LANL-97A substorm signature appears to end at $\sim 1648$ UT. Typically this event caused an approximately $15 \mathrm{~dB}$ effect in the NTSCasey signal, $1 \mathrm{~dB}$ of absorption in the Macquarie Island riometer, and a $20-40^{\circ}$ phase advance in the radio wave signals received at Dunedin.

[14] In Table 1 we show a list of six substorm events that have produced notable phase increases in the Dunedin radio wave data and two that showed very small effects at Dunedin. The columns represent the time of the injection as determined from the LANL data, the delay to onset time observed in the Macquarie Island riometer measurements, the size and the duration of the phase advance observed in the Dunedin subionospheric recordings, and the delay of the phase advance onset time at Dunedin compared with the Macquarie Island riometer onset time. In the current study period (January 2006 to December 2007) we have identified six significant $\left(>10^{\circ}\right)$ phase advance events at Dunedin, all of which occurred in the months of February to April, and no $>10^{\circ}$ phase advance events outside these months despite good substorm signatures being observed on occasions by all of the other experiments. Typically the phase advances are $\sim 50^{\circ}$, which is much larger than nighttime phase changes associated with whistler-induced electron precipitation [Lev-Tov et al., 1996; Clilverd et al., 1999; Rodger et al., 2007b] and comparable with large storm effects [Thomson et al., 2007] driven by plasmaspheric hiss-induced precipitation [Rodger et al., 2007a].

[15] The average substorm occurrence time in Table 1 is just after magnetic midnight, and the delay between LANL97A and the Macquarie riometer signature is typically $0.10-0.15 \mathrm{~h}(6-9 \mathrm{~min})$. On average the Macquarie riometer absorption and the Dunedin phase advances last for the same time, that is, $\sim 1.5 \mathrm{~h}$. In five out of the eight events the Dunedin phase advance onset occurs at the same time as the Macquarie riometer absorption onset, however in one event (27 February 2007) there is no delay between the
Macquarie riometer, LANL-97A, and Casey amplitude but a $\sim 40$ min delay to the Dunedin phase advance event.

\section{Discussion}

\subsection{High-Latitude Precipitation Fluxes}

[16] Figure 4 shows the diurnal variation in amplitude of NTS received at Casey. Mesospheric ionization effects on VLF/LF wave propagation can be modeled using the Long Wave Propagation Code (LWPC) [Ferguson and Snyder, 1990]. LWPC models VLF signal propagation from any point on Earth to any other point. Given electron density profile parameters for the upper boundary conditions, LWPC calculates the expected amplitude and phase of the VLF signal at the reception point. In Figure 4 the diamonds indicate undisturbed LWPC model amplitude values for the path using the Thomson [1993] daytime model ionosphere, and the Thomson et al. [2007] nighttime model ionosphere. The substorm effect at Casey can be seen at 1300-1400 UT as a sudden decrease in amplitude of $\sim 12 \mathrm{~dB}$, lasting $\sim 1 \mathrm{~h}$.

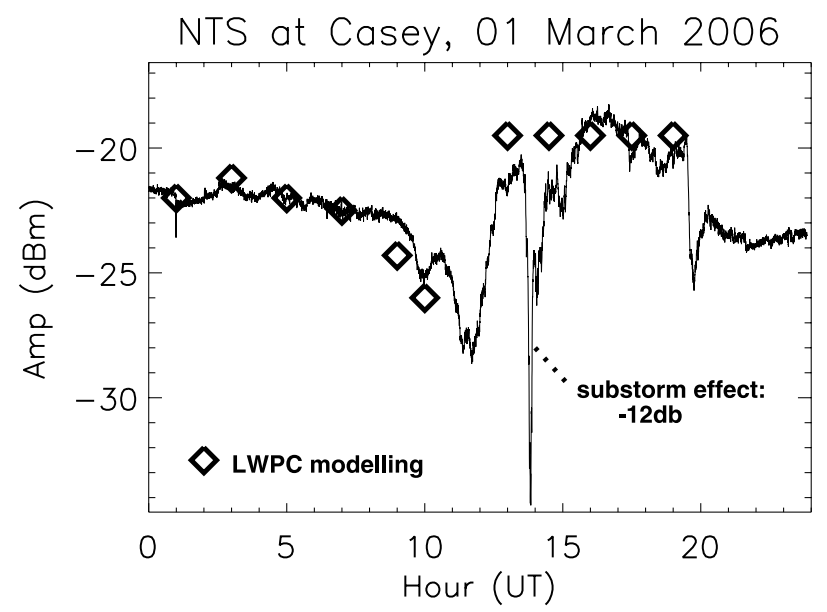

Figure 4. The diurnal variation in amplitude of the NTS received at Casey on 1 March 2006. The diamonds indicate undisturbed Long Wave Propagation Code (LWPC) model amplitude values for the path using the Thomson [1993] daytime model ionosphere and the Thomson et al. [2007] nighttime model ionosphere. The substorm effect can be seen at $\sim 1300-1400$ UT as a sudden decrease in amplitude of $>10 \mathrm{~dB}$, lasting $\sim 1 \mathrm{~h}$. 

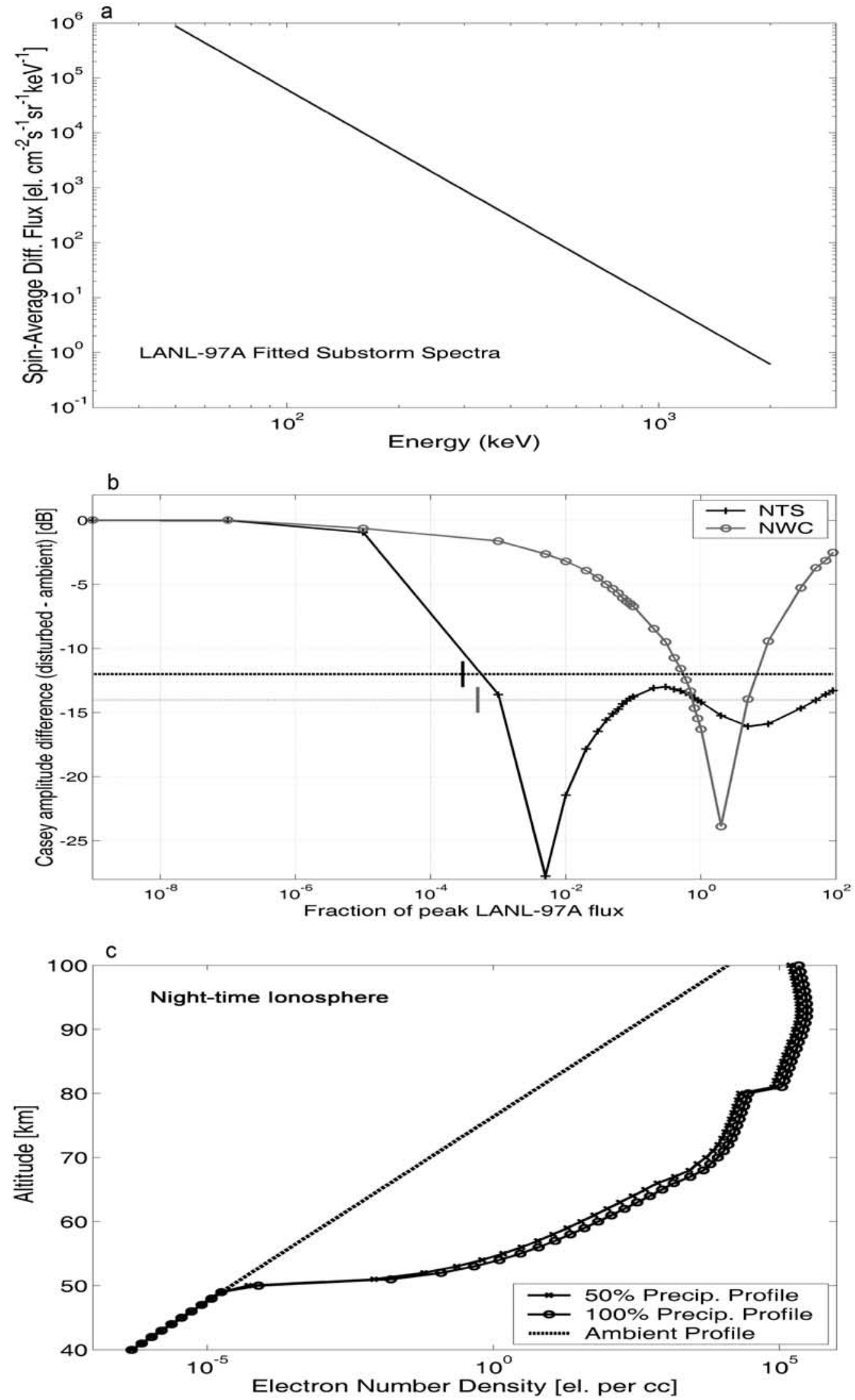

Figure 5 
Figure 4 shows that we are able to model the normal behavior of the diurnal variation of the NTS amplitude changes observed at Casey. This knowledge can be used as a starting point in investigating the substorm-induced changes. In Figures 2 and 3 there is no delay between the LANL-97A substorm flux enhancements and the amplitude changes of NTS received at Casey. The propagation path passes through the expected region of electron precipitation during the substorm, and close to the LANL-97A southern geomagnetic footprint location (Figure 1), so the ionization changes in that region should be responsible for the amplitude changes observed. Thus we should be able to model the impact on the transmitter signals using precipitation described by LANL-97A fluxes applied on only a central portion of the transmitter-receiver great circle path delimited by the dotted lines at $L=4$ and $L=12.5$ shown in Figure 1 . These higher and lower $L$-shell boundaries are estimated from previous studies of substorm injections patterns [e.g., Friedel et al., 1996] and supported in these cases by the observation of riometer signatures near the lower $L$-shell boundary by the Macquarie Island data.

[17] The ionization rate due to precipitating energetic electrons is calculated by an application of the expressions of Rees [1989], expanded to higher energies on the basis of the work of Goldberg and Jackman [1984]. The energy spectrum shown in Figure $5 \mathrm{a}$ is taken from the fit to the LANL-97A observations during the substorm event shown in Figure 2, using measured fluxes in the energy range $50-2500 \mathrm{keV}$. As the precipitating flux magnitude is unknown, and the topic of this subsection, we consider what electron precipitation flux best reproduces our subionospheric radio wave data for the event on 1 March 2006 using the fitted energy spectrum. For this reason, we made use of a simple ionospheric model to describe the balance of electron number density, $N_{e}$, in the lower ionosphere, based on that given by Rodger et al. [1998], and further described by Rodger et al. [2007a]. We summarize the model here as it is relevant to this paper. The background neutral atmosphere is calculated using the NRLMSISE-00 neutral atmospheric model [Picone et al., 2002]. In the simple Rodger model the evolution of the electron density with time is governed by the equation

$$
\frac{\partial N_{e}}{\partial t}=q-\beta N_{e}-\alpha N_{e}^{2}
$$

where $q$ is the ionization rate, $\alpha$ is the recombination coefficient $\left(\mathrm{m}^{3} \mathrm{~s}^{-1}\right)$, and $\beta$ is the attachment rate $\left(\mathrm{s}^{-1}\right)$. Rodger et al. [2007a] provides expressions for the altitude variation of $\alpha$ and $\beta$, appropriate for nighttime and daytime conditions.

[18] The electron number density profiles determined using the simple ionospheric electron model for varying precipitation flux magnitudes are used as input to the LWPC subionospheric propagation model. They are applied on only a central portion of the transmitter-receiver great circle path delimited by the dotted lines at $L=4$ and $L=12.5$ shown in Figure 1, thus modeling the effect of precipitation on the NTS amplitudes received at Casey. An undisturbed nighttime electron density profile which reproduces the received NTS amplitudes is used as specified by the Wait ionosphere $\beta=0.55 \mathrm{~km}^{-1}$ and $h^{\prime}=85.5 \mathrm{~km}$ for nighttime conditions [Thomson et al., 2007]. The difference in the LWPC-modeled NTS and NWC amplitude changes for varying precipitation magnitudes, represented as fractions of the peak LANL-97A observed flux are shown in Figure 5b. The horizontal dotted line indicates the peak experimentally observed amplitude differences of $-12 \pm 1 \mathrm{~dB}$ at $\sim 1400 \mathrm{UT}$ on 1 March 2006 (an amplitude decrease of $-14 \pm 1 \mathrm{~dB}$ was observed on NWC). The peak experimental NTS amplitude difference is best modeled by a precipitating flux which is $\sim 0.1 \%$ or $30-70 \%$ of the LANL-97A peak flux reported during the substorm, while for NWC it is $50-100 \%$ or $\sim 800 \%$ (the latter being unreasonably high). The results shown indicate that although multiple precipitation flux levels can lead to the same amplitude difference on each transmitter, we expect the $50-70 \%$ precipitating flux value to be the most representative of the actual situation because it is the only solution that matches the observations for both transmitters. In addition, previous work has suggested that values just below or near $100 \%$ are most appropriate. However, in the paragraphs below we also confirm this finding using riometer data. Figure $5 \mathrm{c}$ shows the electron density profile changes induced by the substorm precipitation that ranges from $50 \%$ to $100 \%$ of the LANL-97A flux levels at the peak of the substorm on 1 March 2006.

[19] By calculating height-integrated differential absorption using a method described by Verronen et al. [2006], and using the electron density profile shown in Figure $5 \mathrm{c}$ we can estimate the expected riometer absorption for the Macquarie Island riometer. We find that precipitating $100 \%$ of the peak LANL-97A $>30 \mathrm{keV}$ flux during the substorm gives $4.5 \mathrm{~dB}$ of absorption, and that we require $50 \%$ to reproduce the observed $3 \mathrm{~dB}$ peak substorm effect shown in Figure 2. A separate calculation based on an implementation of the Appleton-Hartree equation, where "merged" electron density and collision frequency profiles are integrated over height range [Beharrell and Honary, 2008], suggests that $90 \%$ of the peak LANL-97A fluxes are required. These values are consistent with the flux values determined by fitting the radio wave propagation observations (Figure 5b). Presumably, VLF, electromagnetic ion cyclotron (EMIC), or other waves are responsible for continuously moving the majority of the injected particles into the loss cone, which would explain why the LANL and precipitating fluxes are comparable. But we note that the pitch angle scattering would have to be operating in a very efficient manner. The other alternative is that the substorm mechanism has a strong preference toward the injection of

Figure 5. (a) The LANL energy spectra during the peak of the 1 March 2006 substorm injection. (b) The effect of LANL97A electron precipitation on the NTS-Casey amplitudes as the fluxes are varied. The maximum amplitude change observed at Casey is represented by the horizontal dashed line, indicating a maximum precipitation flux of $\sim 50-100 \%$ of the LANL-97A peak spin-averaged differential flux. (c) The corresponding changes in the electron density profile at substorm latitudes during the peak fluxes of the event of 1 March 2006. 


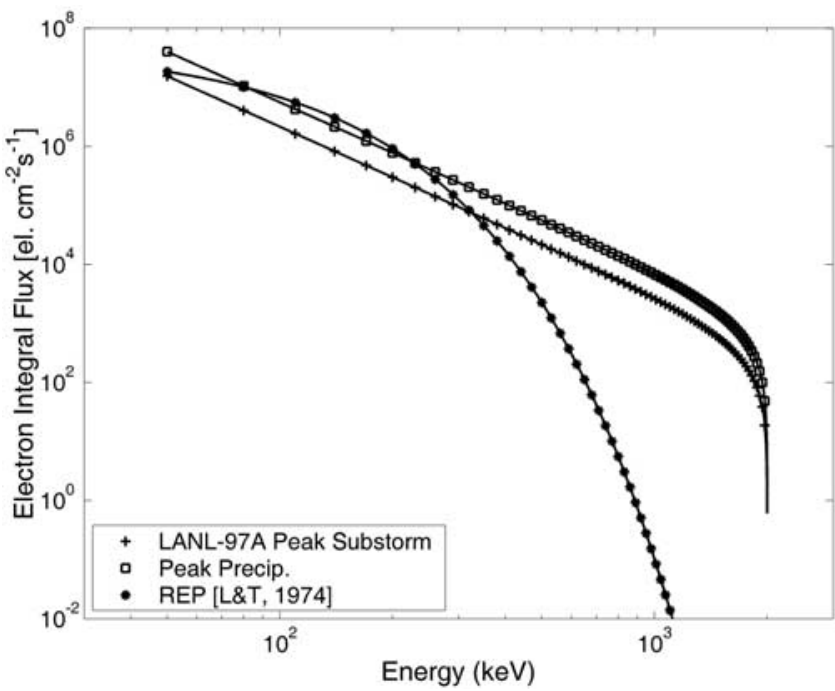

Figure 6. The LANL trapped flux energy spectra for the 1 March 2006 substorm injection (squares), compared with the $E_{0}=50 \mathrm{keV} e$-folding spectra estimated by Larsen and Thomas [1974] from a relativistic electron precipitation event observed by the ESRO 1A satellite (circles). The peak substorm-precipitated electron flux determined from the radio wave data is also shown (crosses).

electrons with pitch angles that lie inside or, very close to, the loss cone.

[20] In Figure 6 the fitted energy spectra of both the $100 \%$ LANL-97A peak trapped flux and the 50\% precipitated flux are compared with the $50 \mathrm{keV} e$-folding energy spectrum reported by Larsen and Thomas [1974]. There is good agreement between the fit to the LANL-97A trapped flux and the $50 \mathrm{keV} e$-folding spectrum up to $\sim 400 \mathrm{keV}$. However, for energies $>400 \mathrm{keV}$ the LANL-97A spectrum has significantly higher fluxes. To reproduce the substorm signature in the radio wave data the $50 \%$ precipitated flux produces $1.5 \times 10^{5} \mathrm{el} . \mathrm{cm}^{-2} \mathrm{~s}^{-1} \mathrm{sr}^{-1}$ for $>200 \mathrm{keV}$ energies. This is substantially greater that the fluxes of $\geq 10^{3}$ el. $\mathrm{cm}^{-2} \mathrm{~s}^{-1} \mathrm{sr}^{-1}$ for $>200 \mathrm{keV}$ electrons reported by [Thorne and Larsen, 1976]. The precipitated electron spectrum also has higher fluxes than the $50 \mathrm{keV} e$-folding spectra for energies $>400 \mathrm{keV}$, but without these highenergy fluxes we are unable to accurately model the radio propagation effects of the substorm for precipitating fluxes which were $50 \%$ of the peak value reported by LANL-97A: the difference between using the high-energy flux component of the spectra or not being $7 \mathrm{~dB}$ for NWC and $2 \mathrm{~dB}$ for NTS. These highly relativistic electrons will penetrate deeply into the atmosphere and impact the chemistry of the stratosphere and lower mesosphere (see Turunen et al. [2008] for a review of the potential chemical effects of relativistic electron precipitation into the middle atmosphere).

[21] The time delay between the beginning of the substorm injection in the LANL-97A particle data at $L=6.6$ and the lower latitude Macquarie Island riometer data $(L=$ 5.4 ) is typically $6-9 \mathrm{~min}$. Figure 1 shows that the LANL geomagnetic field line footprint location and the riometer location are separated by $\sim 20^{\circ}$ of longitude and $\sim 8^{\circ}$ of latitude. However, the longitudinal expansion of the sub- storm precipitation is fast and typically covers $\sim 100^{\circ}$ in the first 15 min [Berkey et al., 1974]. Thus, potentially $\sim 3 \mathrm{~min}$ of delay could occur between the two sites as a result of longitudinal expansion of the precipitation region. However, the results from Sarris et al. [2002] suggest that most of the 6-9 min delay is consistent with injection propagation times from $L=6.6$ to $L=5.4\left(1.2 \mathrm{R}_{\mathrm{e}}\right.$ at $25 \mathrm{~km} \mathrm{~s}^{-1}$ takes $5 \mathrm{~min})$.

\subsection{Midlatitude Phase Advance Signatures}

[22] In section 3 we showed that there were subionospheric phase advances observed at the midlatitude recording site in Dunedin which were associated with the substorms observed at higher $L$ shells. Although the midlatitude phase advances were delayed with respect to the substorm onset timing shown by the high-latitude observations from LANL-97A $(L=6.6)$ and the Casey subionospheric data, they were not delayed with respect to the Macquarie Island riometer observations $(L=5.4)$. This midlatitude substorm phase advance signature has not been reported before and may be caused by one of several mechanisms.

[23] The most obvious candidate mechanism is direct precipitation from the substorm injection event. We note that this mechanism seems unlikely as previous work showed that the low-latitude boundary of electron precipitation from substorms determined by riometers is $L=4$, as we discussed in section 1 [Berkey et al., 1974]. However, it is possible that lower latitude electron precipitation is caused by electromagnetic ion cyclotron waves (EMIC) associated with a region of high plasmaspheric electron density gradients. The effectiveness of the mechanism has recently been shown by Clilverd et al. [2007], with signatures occurring in the phase of subionospherically propagating radio waves just as reported in this study. This electron precipitation mechanism would require EMICinduced precipitation to be triggered by the substorm at a density gradient region either well inside the plasmasphere, or from a compressed plasmapause. The EMIC triggered electron precipitation at $L \sim 2.5$ inferred by Clilverd et al. [2007] was caused by the intense coronal mass ejection event of 21 January 2005 [Clilverd et al., 2006a] and thus was associated with a very large storm event, rather than the substorm events considered in the current paper. Observational evidence of the presence of EMIC waves at higher $L$ shells during these substorms comes from two of the Automated Geophysical Observatories (AGOs) pulsation magnetometers in Antarctica, covering $L=6-8$, which are at such high $L$ shells that they do not support or refute the possibility of EMIC waves at $L \sim 2.7$.

[24] If direct electron precipitation is causing the midlatitude phase advances seen in Figures 2 and 3 then we would expect to observe some signature of it on the riometer data from Dunedin (see Figure 1 for the NWC and NTS paths to Dunedin). Figure 7 shows a substorm-associated phase advance that occurred on 10 March 2005. Although the format is similar to that of Figures 2 and 3, Figure 7d shows riometer absorption data from Dunedin $(L=2.8)$. No Dunedin riometer data is available for 2006 , so we have to show data from 2005 which was before our instrument at Casey was operational, and consequently substorm events from 2005 were not initially selected for this study. Figure 7 

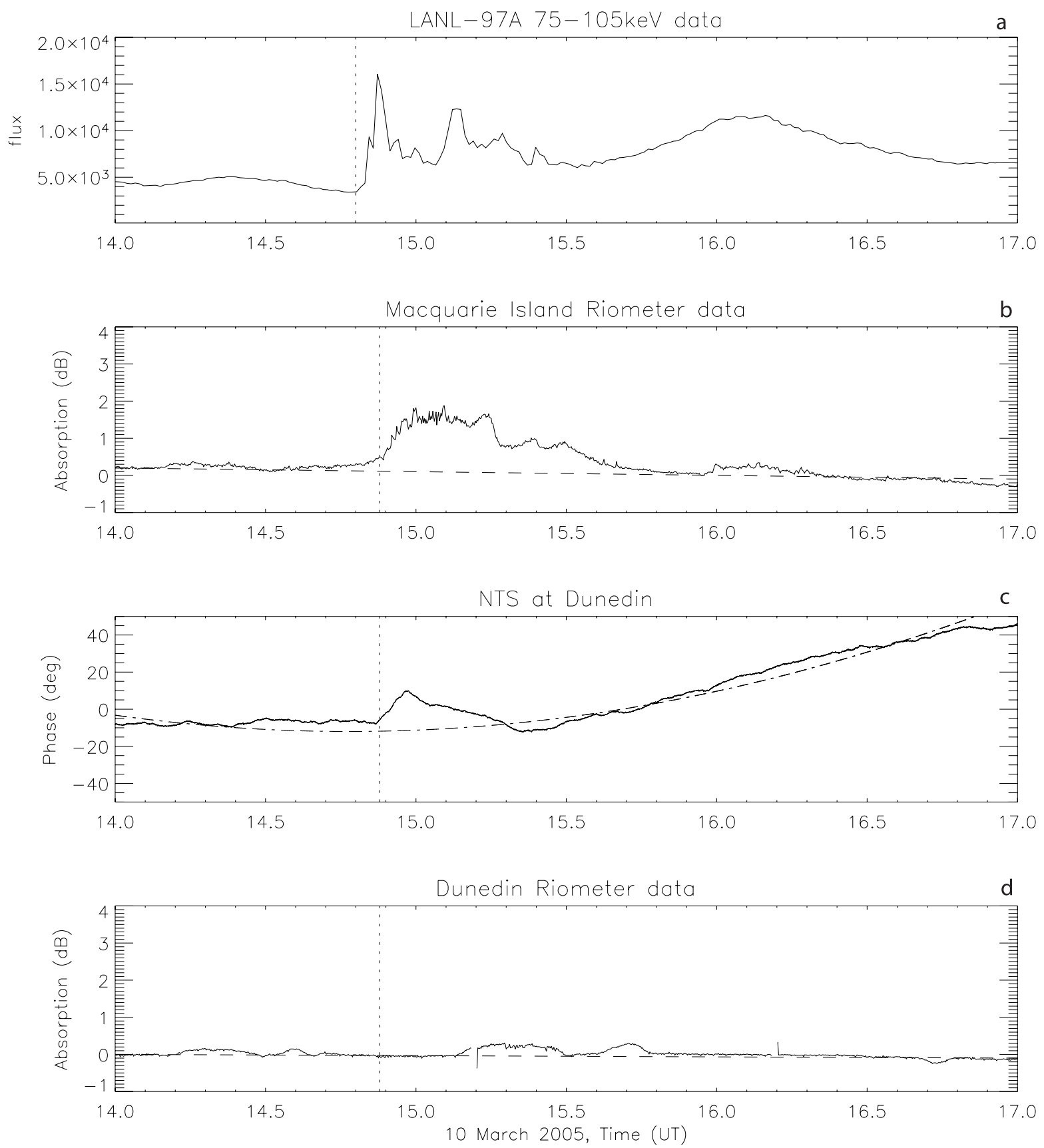

Figure 7. (a-d) A plot of the effects of a substorm on 10 March 2005. The format is similar to that of Figure 2 but with Figure 7d representing the Dunedin riometer data. No NWC or NTS-Casey amplitude data are available for this event.

shows that a substorm injection event occurred in the LANL data at $1448 \mathrm{UT}$, with a resultant $1.5 \mathrm{~dB}$ absorption signature on the Macquarie Island riometer seen $\sim 5$ min later. A small phase advance is seen at the same time on NTS received at Dunedin, all of which is consistent with the pattern of events shown in Figures 2 and 3. In contrast, the Dunedin riometer shows no significant absorption coincident with the event timing. Thus we conclude that either there is no direct electron precipitation occurring at $L=2.4-2.8$ in this event, or that the energy of the precipitating electrons is so high that no significant absorption is produced in the riometer data. An energy spectra dominated by relativistic electrons (energies 1-2 MeV) is consistent with the expected spectrum driven by EMIC [Loto'aniu et al., 2006], which might produce changes in subionospheric propagation without creating a significant change in riometer absorptions. EMIC waves have been associated with substorm particle injections [Erlandson and Ukhorskiy, 2001].

[25] Central to the question of the mechanism that drives the midlatitude phase advances is the observation that there is little timing delay between the Macquarie Island riometer data, and the Dunedin subionospheric phase advances. This is clearly not consistent with the propagation of an injection 
event, which the results of Sarris et al. [2002] suggest would take an additional $\sim 20 \mathrm{~min}$. If direct precipitation is occurring then it is being triggered when the injection arrives at Macquarie Island latitudes. One possibility is an enhancement of EMIC wave activity in the plasmasphere, triggered as the injection reaches the plasmapause (or just outside this region). Another possibly, summarized by Rodger and Clilverd [2008] is the enhancement of, and then propagation of, waves from outside the plasmapause into the plasmasphere: Bortnik et al. [2008] showed that chorus outside the plasmapause could appear inside the plasmasphere as plasmaspheric hiss with delay times of only a few seconds. In addition, Rodger et al. [2007a] showed that plasmaspheric hiss could produce significant electron precipitation at $L \sim 3.0$ during geomagnetic storms, although the hiss provided an electron precipitation energy spectrum with significant fluxes of electrons $<1 \mathrm{MeV}$ which would not necessarily agree with the Dunedin riometer data shown in Figure 7.

[26] Another mechanism that could produce a substormassociated phase advance on obliquely propagating radio waves is off great circle-path scattering from the ionization generated in the substorm precipitation zone between $L=4$ and $L=12$. The patch of substorm ionization located below the normal altitude of the $D$ region lower boundary could scatter the radio waves from the transmitters in Australia back toward the receiver in Dunedin and constructively/ destructively interfere with the direct signal from transmitter to receiver [e.g., Dowden and Adams, 1993; Clilverd et al., 2002]. Off-path scattering from sprites has only been reported from ionization patches located within $\sim 200 \mathrm{~km}$ of the propagation path. In addition, the high-angle off-path scattering requires regionally small, electrically "dense," ionization patches rather than the spatially large features expected from substorm precipitation zone extending from $L=4$ to higher $L$ shells.

[27] Finally, we note one final characteristic of substormassociated phase advances, which is the preponderance of the observations occurring in the autumn equinox (February to April). Six of the eight events shown in Table 1 occur during this time frame, while the substorm events investigated outside this period showed either no phase change or very little $\left(<10^{\circ}\right)$ change. The observed seasonal preference in substorm-associated subionospheric phase advances could be due to changes in the efficiency of the mechanism which is altering the electrical properties of the lower $D$ region, which we monitor by the subionospheric propagation. Another possibility is that the mechanism is occurring with the same efficiency outside those months, but that there is a lack of sensitivity in the underlying radio wave propagation conditions to those ionospheric alterations. Answering these questions requires future studies which identify the mechanism by which the midlatitude ionosphere is modified by high-latitude substorms.

\section{Summary}

[28] Data from high-latitude locations (Casey and Macquarie Island, Australian Antarctic Division) and the geostationary satellite LANL-97A, all in the region south of Australia and New Zealand, are used to describe and model high-latitude electron precipitation driven by substorm injection events. We find that electron precipitation imposed over the latitude range associated with substorm precipitation, and with the energy spectrum observed by the LANL-97A instrument, can be used to model the subionospheric radio wave substorm signature seen at Casey. The maximum required precipitation rate into the atmosphere is found to be $50-90 \%$ of the peak fluxes measured by the LANL-97A spacecraft. The electron energy spectrum is consistent with an $e$-folding energy of $50 \mathrm{keV}$ for energies $<400 \mathrm{keV}$, but also contains higher fluxes of electrons from 400 to $2000 \mathrm{keV}$.

[29] Additionally, we present radio wave data recorded at midlatitudes, that is, Dunedin, New Zealand, to show that there is a concurrent substorm-associated phase advance signature at $L<2.8$, but that no clear signature of any substorms can be detected in a riometer also located in Dunedin. Three mechanisms have been discussed to explain the phase advances, including the precipitation of radiation belt electrons, both by direct substorm electron precipitation or possibly indirectly by electromagnetic ion cyclotron wave interactions, and the distant scattering of radio waves by the ionization feature at $L>4$ in a similar way to lowlatitude Trimpi or VLF Sprites. We find that the most likely mechanism considered in this paper is the triggering of energetic electron precipitation during the substorm, consistent with EMIC wave-particle interactions, although the presence of these waves has not been directly observed.

[30] Acknowledgments. The authors would like to thank Bill and Helen Dunford for their generous support during this work. The Casey data are supported by AAD project ASAC 1324. We would also like to acknowledge the use of the AAD data system for the provision of the Macquarie Island Riometer data, available at http://www.ips.gov.au/ World_Data_Centre/1/8. We would like to acknowledge Hiroshi Fukunishi of Tohoku University, Sendai, Japan, for providing the summary AGO Pc 1-2 data. The LANL data were kindly provided by the Los Alamos National Laboratory from http://leadbelly.lanl.gov/lanl_ep_data/. A. S. would like to acknowledge funding support from the Finnish Academy.

[31] Zuyin Pu thanks Xinlin Li and David Nunn for their assistance in evaluating this paper

\section{References}

Bailey, D. K. (1968), Some quantitative aspects of electron precipitation in and near the auroral zone, Rev. Geophys., 6, 289-346.

Baker, D. N., W. Aiello, J. R. Asbridge, R. D. Belian, P. R. Higbie, R. W. Klebesadel, J. G. Laros, and E. R. Tech (1985), Los Alamos energetic particle sensor systems at geostationary orbit, AIAA-1985-243, Am. Inst. of Aeronaut. and Astronaut., Reston, Va.

Barr, R., D. L. Jones, and C. J. Rodger (2000), ELF and VLF radio waves, J. Atmos. Sol. Terr. Phys., 62, 1689-1718, doi:10.1016/S13646826(00)00121-8.

Beharrell, M. J., and F. Honary (2008), A new method for deducing the effective collision frequency profile in the D-region, J. Geophys. Res. 113, A05303, doi:10.1029/2007JA012650.

Belian, R. D., G. R. Gisler, T. Cayton, and R. Christensen (1992), High-Z energetic particles at geostationary orbit during the great solar proton event series of October 1989, J. Geophys. Res., 97, 16,897-16,906.

Berkey, F. T., V. M. Driatskiy, K. Henriksen, B. Hultqvist, D. H. Jelly, T. I Shchuka, A. Theander, and J. Yliniemi (1974), A synoptic investigation of particle precipitation dynamics for 60 substorms in IQSY (19641965) and IASY (1969), Planet. Space Sci., 22, 255-307, doi:10.1016/ 0032-0633(74)90028-2.

Bortnik, J., R. M. Thorne, and N. Meredith (2008), The unexpected origin of plasmaspheric hiss from discrete chorus emissions, Nature, 452, 6266, doi:10.1038/nature06741.

Clilverd, M. A., R. F. Yeo, D. Nunn, and A. J. Smith (1999), Latitudinally dependent Trimpi effects: Modeling and observations, J. Geophys. Res., $104,19,881-19,887$

Clilverd, M. A., D. Nunn, S. J. Lev-Tov, U. S. Inan, R. L. Dowden, C. J. Rodger, and A. J. Smith (2002), Determining the size of lightning- 
induced electron precipitation patches, J. Geophys. Res., 107(A8), 1168, doi:10.1029/2001JA000301.

Clilverd, M. A., C. J. Rodger, and T. Ulich (2006a), The importance of atmospheric precipitation in storm-time relativistic electron flux drop outs, Geophys. Res. Lett., 33, L01102, doi:10.1029/2005GL024661.

Clilverd, M. A., A. Seppälä, C. J. Rodger, N. R. Thomson, P. T. Verronen, E. Turunen, T. Ulich, J. Lichtenberger, and P. Steinbach (2006b), Modeling polar ionospheric effects during the October-November 2003 solar proton events, Radio Sci., 41, RS2001, doi:10.1029/2005RS003290.

Clilverd, M. A., C. J. Rodger, R. M. Millan, J. G. Sample, M. Kokorowski, M. P. McCarthy, T. Ulich, T. Raita, A. J. Kavanagh, and E. Spanswick (2007), Energetic particle precipitation into the middle atmosphere triggered by a coronal mass ejection, J. Geophys. Res., 112, A12206, doi:10.1029/2007JA012395.

Dowden, R. L., and C. D. D. Adams (1993), Size and location of lightninginduced ionisation enhancements from measurement of VLF phase and amplitude perturbations on multiple antennas, J. Atmos. Terr. Phys., 55, 1335-1359, doi:10.1016/0021-9169(93)90102-5.

Erlandson, R. E., and A. J. Ukhorskiy (2001), Observations of electromagnetic ion cyclotron waves during geomagnetic storms: Wave occurrence and pitch angle scattering, J. Geophys. Res., 106(A3), 3883-3895.

Ferguson, J. A., and F. P. Snyder (1990), Computer programs for assessment of long wavelength radio communications, Tech. Doc. 1773, Natl Ocean Syst. Cent., San Diego, Calif.

Friedel, R. H. W., A. Korth, and G. Kremser (1996), Substorm onsets observed by CRRES: Determination of energetic particle source regions, J. Geophys. Res., 101, 13,137-13,154.

Goldberg, R. A., and C. H. Jackman (1984), Nighttime auroral energy deposition in the middle atmosphere, J. Geophys. Res., 89(A7), 55815596.

Helliwell, R. A., J. P. Katsufrakis, and M. L. Trimpi (1973), Whistlerinduced amplitude perturbations in VLF propagation, J. Geophys. Res., $78,4679-4688$

Jelly, D., and N. Brice (1967), Changes in the Van Allen radiation associated with polar substorms, J. Geophys. Res., 72, 5919-5931.

Larsen, T. R., and G. R. Thomas (1974), Energy spectra measured during a relativistic electron precipitation event on 2 February 1969, J. Atmos. Terr. Phys., 36, 1613-1622, doi:10.1016/0021-9169(74)90199-8.

Lev-Tov, S. J., U. S. Inan, A. J. Smith, and M. A. Clilverd (1996), Characteristics of localized ionospheric disturbances inferred from VLF measurements at two closely spaced receivers, J. Geophys. Res., 101, $15,737-15,747$

Little, C. G., and H. Leinbach (1959), The riometer: A device for the continuous measurements of ionospheric absorption, Proc. IRE, 37, $315-320$.

Loto'aniu, T. M., R. M. Thorne, B. J. Fraser, and D. Summers (2006), Estimating relativistic electron pitch angle scattering rates using properties of the electromagnetic ion cyclotron wave spectrum, J. Geophys. Res., 111, A04220, doi:10.1029/2005JA011452.

Picone, J. M., A. E. Hedin, D. P. Drob, and A. C. Aikin (2002), NRLMSISE-00 empirical model of the atmosphere: Statistical comparisons and scientific issues, J. Geophys. Res., 107(A12), 1468, doi:10.1029/ 2002JA009430

Rees, M. H. (1989), Physics and Chemistry of the Upper Atmosphere, Cambridge Univ. Press, New York.

Rodger, C. J., and M. A. Clilverd (2008), Magnetospheric physics: Hiss from the chorus, Nature, 452(7183), 41-42, doi:10.1038/452041a.

Rodger, C. J., O. A. Molchanov, and N. R. Thomson (1998), Relaxation of transient ionization in the lower ionosphere, J. Geophys. Res., 103(A4), $6969-6975$
Rodger, C. J., M. A. Clilverd, N. R. Thomson, R. J. Gamble, A. Seppälä, E. Turunen, N. P. Meredith, M. Parrot, J. A. Sauvaud, and J.-J. Berthelier (2007a), Radiation belt electron precipitation into the atmosphere: Recovery from a geomagnetic storm, J. Geophys. Res., 112, A11307, doi:10.1029/2007JA012383.

Rodger, C. J., C. F. Enell, E. Turunen, M. A. Clilverd, N. R. Thomson, and P. T. Verronen (2007b), Lightning-driven inner radiation belt energy deposition into the atmosphere: Implications for ionisation-levels and neutral chemistry, Ann. Geophys., 25, 1745-1757.

Rosenberg, T. J., L. J. Lanzerotti, D. K. Bailey, and J. D. Pierson (1972), Energy spectra in relativistic electron precipitation events, J. Atmos. Terr. Phys., 34, 1977-1990, doi:10.1016/0021-9169(72)90179-1.

Sandholt, P. E., et al. (2002), Multistage substorm expansion: Auroral dynamics in relation to plasma sheet particle injection, precipitation, and plasma convection, J. Geophys. Res., 107(A11), 1342, doi:10.1029/ 2001JA900116.

Sarris, T. E., X. Li, N. Tsaggas, and N. Paschalidis (2002), Modeling energetic particle injections in dynamic pulse fields with varying propagation speeds, J. Geophys. Res., 107(A3), 1033, doi:10.1029/ 2001JA900166.

Thomson, N. R. (1993), Experimental daytime VLF ionospheric parameters, J. Atmos. Terr. Phys., 55, 173-184, doi:10.1016/0021-9169(93) 90122-F.

Thomson, N. R., C. J. Rodger, and M. A. Clilverd (2005), Large solar flares and their ionospheric $D$ region enhancements, J. Geophys. Res., 110, A06306, doi:10.1029/2005JA011008

Thomson, N. R., M. A. Clilverd, and W. M. McRae (2007), Nighttime ionospheric $D$ region parameters from VLF phase and amplitude, J. Geophys. Res., 112, A07304, doi:10.1029/2007JA012271.

Thorne, R. M., and T. R. Larsen (1976), An investigation of relativistic electron precipitation events and their association with magnetic substorm activity, J. Geophys. Res., 81, 5501-5506.

Turunen, E., et al. (2008), Impact of different energies of precipitating particles on $\mathrm{NO}_{x}$ generation in the middle and upper atmosphere during geomagnetic storms, J. Atmos. Sol. Terr. Phys., in press.

Verronen, P. T., T. Ulich, E. Turunen, and C. J. Rodger (2006), Sunset transition of negative charge in the D-region ionosphere during highionization conditions, Ann. Geophys., 24, 187-202.

J. Bähr, C. J. Rodger, and N. R. Thomson, Department of Physics, University of Otago, P.O. Box 56, Dunedin 9054, New Zealand. (bahr@physics.otago.ac.nz; crodger@physics.otago.ac.nz; n thomson@ physics.otago.ac.nz)

J. Brundell, Dunedin, New Zealand. (james@brundell.co.nz)

M. A. Clilverd, N. Cobbett, T. Moffat-Griffin, and A. Seppälä, Physical Sciences Division, National Environmental Research Council, British Antarctic Survey, High Cross, Madingley Road, Cambridge CB3 0ET, UK (macl@bas.ac.uk; nco@bas.ac.uk; tmof@bas.ac.uk; annika.seppala@fmi.fi)

R. H. W. Friedel, Los Alamos National Laboratory, Bikini Atoll Road, SM 30, Los Alamos, NM 87545, USA. (friedel@lanl.gov)

A. J. Kavanagh, Space Plasma Environment and Radio Science Group, Department of Communication Systems, InfoLab 21, Lancaster University, Lancaster LA1 4WA, UK. (a.j.kavanagh@lancaster.ac.uk)

F. W. Menk, School of Mathematical and Physical Sciences, University of Newcastle, Callaghan, NSW 2308, Australia. (fred.menk@newcastle. edu.au) 